\title{
Long-term effects of stem girdling on needle structure in Scots pine
}

\author{
Roman Gebauer (1), \\ Roman Plichta ${ }^{(1)}$, \\ Jiří Foit ${ }^{(1)}$, \\ Václav Čermák ${ }^{(1)}$, \\ Josef Urban ${ }^{(1-2)}$
}

\begin{abstract}
Stem girdling is the process of completely removing a strip of cork and phloem tissue. Phloem is the living tissue which serves as the main long-distance pathway for transporting carbohydrates produced during photosynthesis to all parts of the plant where needed, from source leaves to sinks. Stem girdling has been used to study several functional aspects of phloem and their direct im pacts on tree growth. Although both photosynthesis and transpiration processes take place in needles, no studies exist which investigate the effect of source-sink disturbance on needle structure. In this study, we evaluated changes in needle morphology and anatomy in current-year Scots pine needles 227 and 411 days after girdling (DAG). Although the studied needle parameters recorded 227 DAG were from 2 to $20 \%$ higher than the same parameters in control needles, the differences were not significant. On the other hand, needles 411 DAG were thinner, with decreased cross-sectional areas, phloem areas, vascular cylinder areas, needle dry mass, needle density, and needle flatness when compared to control needles. Marked variations in needle growth were observed 411 DAG, with a smaller number of correlations among almost all studied needle parameters in needles 411 DAG when compared to control needles or needles 227 DAG. Structural development determining needle flatness, needle density, and leaf mass per area (LMA) appeared to have driving factors that were independent of the other studied needle parameters, as correlations with other parameters were not significant in any treatment. The changes in overall needle structure observed after long-term stem girdling provide new insights into the processes that occur as a result of source-sink disturbances. This type of data could be helpful, for example, in studies specifically focused on phloem transport, tree carbon relationships, or investigations modeling gas exchange. Our study might also support gene expression studies, which could provide further knowledge about the regulatory mechanisms that determine needle size and structural form.
\end{abstract}

Keywords: Anatomy, Cross-section, Morphology, Pinus sylvestris, Phloem, Source-Sink Disturbance

on apical dominance (Wilson \& Gartner 2002), on the phloem-xylem connection (Zwieniecki et al. 2004), on processes involving bark regeneration (Mwange et al. 2003, Pang et al. 2008), and relationships between tree water and carbon status (Johnsen et al. 2007, De Schepper \& Steppe 2011). Phloem girdling has also been practiced in forestry as a pre-harvest treatment to alter wood properties by manipulating annual ring width, wood density, the duration of cambial activity, and latewood production (Noel 1970, Wilson \& Gartner
(1) Mendel University in Brno, Faculty of Forestry and Wood Technology, Zemedelská 3, Brno, 61300 (Czech Republic); (2) Siberian Federal University, Krasnoyarsk (Russia)

@ Roman Gebauer (gebo@email.cz)

Received: Oct 10, 2017 - Accepted: Apr 05, 2018

Citation: Gebauer R, Plichta R, Foit J, Cermák V, Urban J (2018). Long-term effects of stem girdling on needle structure in Scots pine. iForest 11: 476-481. - doi: 10.3832/ifor2648-011 [online 2018-07-02]

Communicated by: Silvano Fares
2002, Domec \& Pruyn 2008). Despite its ecological significance, studies about the anatomical and physiological effects of stem girdling in forest trees are scarce compared to those carried out on branch girdling in horticulture (Lopéz et al. 2015).

The effects of stem girdling differ from those of branch girdling in that it promotes carbohydrate accumulation above the girdle and prevents carbohydrates from being transported to the roots (Lopéz et al. 2015). The first visual symptom after girdling is an increase in stem diameter above the girdle due to the growth of bark and xylem stimulated by the accumulation of carbohydrates, coupled with the interruption of stem growth below the girdle (Daudet et al. 2005, De Schepper et al. 2010). Roots are gradually depleted of their carbohydrate reserves and suffer starvation (Weaver \& McCune 1959). Although the structural adaptation of stems to disruption in phloem long-distance transport has been studied in detail, to the best of our knowledge no research exists on the structural adaptation of leaves or needles in response to stem girdling. Only a handful of studies have focused on the development 
of leaf area and leaf mass per unit area (LMA) after girdling (Day \& DeJong 1990, Domec \& Pruyn 2008) and only one study focused on needle xylem structure development after stem girdling (Gebauer et al. 2017). It was observed that long-term stem girdling led to a reduction in the theoretical hydraulic conductivity of Scots pine needles, and in their xylem area and number of tracheids (Gebauer et al. 2017). The physiological adaptation of leaves after girdling, on the other hand, has been studied more thoroughly. The accumulation of carbohydrates in leaves after girdling leads to the consequent down-regulation of photosynthetic rates (Rivas et al. 2007), decreased stomatal conductance and transpiration (Sellin et al. 2013), the accumulation of abscisic acid in leaves (Setter et al. 1980), and an increase in leaf water potential (Williams et al. 2000). It has also recently been shown that non-structural carbohydrates (NSC) regulate the gene expression involved in several plant metabolic functions (Hara et al. 2003, Murakami et al. 2008). Such a broad range of physiological adaptations in leaves after stem girdling should also trigger structural adaptation. In higher plants, the coordination of metabolism and morphogenesis often depends on hormone signals from one part of the plant to another (Taiz \& Zeiger 2002). For example, the transport of auxin from the shoot to the root affects various developmental processes, including stem elongation and leaf senescence (Taiz \& Zeiger 2002). Thus, the other interesting question is how the disruption of the phloem transport of plant hormones affects the interplay among the various highly correlated structural parameters of leaves. As both photosynthesis and transpiration processes take place in leaves, further knowledge about how leaves adapt to girdling is important for a better understanding of the physiology of the whole tree (Yan et al. 2012).

The aim of this study was to gain an insight into the anatomical and morphological responses of Scots pine (Pinus sylvestris L.) needles to the disturbance of phloem long-distance transport channels. We fo- cused on needle structural development 8 and 14 months after girdling (hereafter referred to as 227 and 411 DAG, days after girdling, respectively). This study follows up on our previous work (Gebauer et al. 2017), in which needle xylem structure, sap flow, and non-structural carbohydrate (NSC) changes after stem girdling were analyzed. We hypothesize that (i) needle growth will increase in response to carbohydrate accumulation 227 DAG, (ii) needle growth will be reduced 411 DAG, as root starvation will lead to decreased sap flow and to a subsequent water shortage in the needles, and (iii) correlations among the studied needle morphological parameters will be different in girdled and control trees.

\section{Material and methods}

\section{Study site and description of the experiment}

The study site is an even-aged mixed coniferous/deciduous forest stand located near Brno (south-east of the Czech Republic - $49^{\circ} 15^{\prime} 39^{\prime \prime} \mathrm{N}, 16^{\circ} 36^{\prime} 20^{\prime \prime} \mathrm{E} ; 340 \mathrm{~m}$ a.s.l.). The mean annual air temperature and precipitation are $8.7^{\circ} \mathrm{C}$ and $490 \mathrm{~mm}$, respectively. In 2014, the mean air temperature was $11.3^{\circ} \mathrm{C}$ and the sum of precipitation was $609 \mathrm{~mm}$. The stand was planted in 1928, with Scots pine (Pinus sylvestris L.) being the dominant tree species. The soil type is mesotrophic Cambisol. Twenty two co-dominant Scots pine trees were selected for detailed analysis. Six trees were selected as controls, 8 trees were stem girdled in summer, on 15 July 2013, and 8 trees were girdled in winter, on 15 January 2014. By the time of the summer girdling, the needles were fully developed in length. Stem cambium was active until September; however, most of the cells in the growth ring had already been formed at the time of summer girdling and a decline in the number of cells upon the enlargement phase suggested a transition from earlywood to latewood formation (Fajstavr et al. 2017). Girdling consisted of removing a 7-10 cm wide band of bark (periderm, cor-

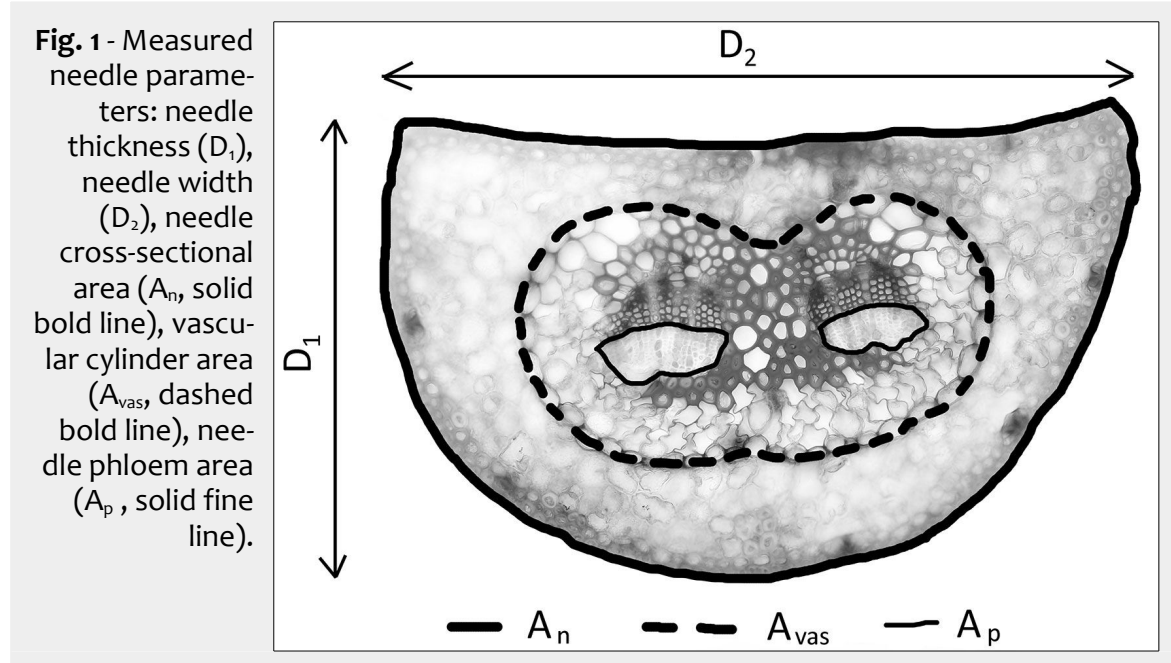

tex, secondary phloem, and cambium) from around the entire stem at a height of $1.3 \mathrm{~m}$ above the ground. The girdled area was completely covered with resin at the end of the experiment. Sap flow was monitored in all experimental trees from 1 April to 30 August 2014, using EMS 51 sap flow meters (EMS Brno, Czech Republic). Current year needles from sun-exposed branches were also used to analyze levels of non-structural carbohydrates (NSC). A detailed description of girdling treatment, sap flow, and NSC analysis is given in Gebauer et al. (2017).

\section{Needle structure analysis}

Five current-year shoots with fully developed needles were sampled from each of the trees. The shoots were obtained from branches at the middle height of the crown. The shoots were facing south and situated on the outer side of the crown. Samples were collected on 30 August 2014 (i.e., 227 or 411 days after girdling, hereafter referred to as DAG). In the field, the samples were fixed in FineFIX ${ }^{\circledast}$ solution (Milestone, Bergamo, Italy). Subsequently, from each of the collected shoots, four randomly selected fascicles (with two needles per fascicle, thus yielding 40 needles per tree) were collected for further needle structure analysis. One needle from each fascicle was used for cross-sectional anatomical analysis, while the second one was scanned immediately after removal from the fixative solution to determine the projected needle area (PLA) and individual needle length $\left(L_{n}\right)$ using the software Image $J^{\circledast}$ (National Institute of Mental Health, Bethesda, Maryland, USA). Scanned needles were then oven dried at $85{ }^{\circ} \mathrm{C}$ for 48 hours to determine needle dry mass (DM). The leaf mass per unit area (LMA) was calculated as the ratio of DM/PLA and the needle density $\left(\mathrm{N}_{\mathrm{D}}, \mathrm{g} \mathrm{cm}^{-3}\right)$ was calculated according to eqn. 1 :

$$
N_{D}=\frac{D M}{A_{n} L_{n}}
$$

Cross-sections for anatomical analyses were taken at the needle base and then examined under an Olympus $\mathrm{BX}_{51^{\circledR}}$ light microscope (Olympus, Tokyo, Japan) at magnifications of up to $\times 400$ and photographed using a Canon EOS $^{\oplus} 1100 \mathrm{D}$ digital camera (Canon Inc., Tokyo, Japan) connected to a computer by means of QuickPhotoMicro 3.1 software (Promicra, Prague, Czech Republic). The following parameters were measured using ImageJ software (Fig. 1): cross-sectional needle area $\left(A_{n}\right)$, vascular cylinder area $\left(A_{\text {vas }}\right)$, phloem area $\left(A_{p}\right)$, needle thickness $\left(D_{1}\right)$, and needle width $\left(D_{2}\right)$. Needle cross-sectional shape (i.e., needle flatness, $F_{n}$ ) was calculated as the ratio of $D_{1} / D_{2}$. A needle with a round or square cross-section would have a value of $F_{n}$ close to 1 , and lower ratios would characterize more flattened needles. 


\section{Statistical analysis}

The linear mixed effect model (LME) employing the restricted maximum likelihood method (REML) was used, where individual trees were specified as a random effect (Zuur et al. 2009). Where appropriate (i.e., for the parameters $D M, L_{n}, L M A, N_{D}$, and PLA), the simple linear model was used. Linear models were also used for correlation matrices. Next, the Tukey's honestly significance difference (HSD) test was used to indicate which treatments differed (significance level 0.05), and p-values assessing the probability of difference between treatments were extracted. The R statistical program (R Core Team 2015) was used for statistical analysis. LME was fitted using the Ime function from the nlme library, while Tukey's test was performed using the glht function from the multcomp library. All acronyms, abbreviations, and symbols are defined in Tab. 1.

\section{Results}

\section{Needle structure}

Although all studied needle structural parameters 227 DAG were slightly higher in girdled than in control trees (except no difference in $F_{n}$ ), these differences were not
Tab. 1 - Overview of the needle parameters, their abbreviations, definitions and units used throughout this study.

\begin{tabular}{|lll|}
\hline Parameter & Explanation & Unit \\
\hline$A_{n}$ & needle cross-sectional area & $\mathrm{mm}^{2}$ \\
\hline$A_{p}$ & needle phloem area & $\mathrm{mm}^{2}$ \\
\hline$A_{\text {vas }}$ & vascular cylinder area & $\mathrm{mm}^{2}$ \\
\hline$D_{1}$ & needle thickness & $\mathrm{mm}$ \\
\hline$D_{2}$ & needle width & $\mathrm{mm}$ \\
\hline$D M$ & needle dry mass & $\mathrm{mg}$ \\
\hline$F_{n}$ & needle flatness $\left(D_{1} / D_{2}\right)$ & - \\
\hline$L_{n}$ & needle length & $\mathrm{mm}^{-2}$ \\
\hline$L M A$ & leaf mass per area (DM/PLA) & $\mathrm{g} \mathrm{m}^{-2}$ \\
\hline$N_{D}$ & needle density & $\mathrm{g} \mathrm{cm}^{-3}$ \\
\hline PLA & needle projected area & $\mathrm{mm}^{2}$ \\
\hline
\end{tabular}

statistically significant (Fig. 2 and Tab. 2). 36 and 30\%, respectively, resulting in a subOnly LMA, which was approximately $9 \%$ stantial decrease in the cross-sectional dihigher in needles 227 DAG than in control mensions of these needles compared to needles, had a $p$-value close to the level of control needles (Fig. 2 and Tab. 2). Needles significance $(p=0.06)$. In contrast, nearly 411 DAG were flatter $\left(F_{n}\right.$ decrease) than all studied needle parameters were signifi- control needles due to substantial decantly changed 411 DAG. On average, nee- creases in $D_{1}$, and not $D_{2}$. Contrary to most dles 411 DAG were shorter, thinner, denser, of the other needle parameters $411 \mathrm{DAG}, L_{n}$ and lighter than control needles by 10, 32, was not significantly different from the 31 , and $16 \%$, respectively $\left(L_{n}, D_{1}, N_{D}, D M\right.$, re- same parameter in control needles (Tab. 2 ). spectively - Fig. 2). Also, the $A_{n}, A_{p}, A_{\text {vas, }}$ and Also, LMA and PLA values in needles 411 $F_{n}$ of needles 411 DAG were lower by 26,52 , DAG and in control needles were similar
Fig. 2 - Means of morphological and anatomical parameters of Scots pine control needles, needles 227 days after girdling (DAG) and needles 411 DAG. Points in grey represent measured data. Vertical bars are $95 \%$ confidence intervals derived from the appropriate model. Parameters that are different at the $5 \%$ significance level are indicated by different letters. See Tab. 1 for an explanation of needle parameters.
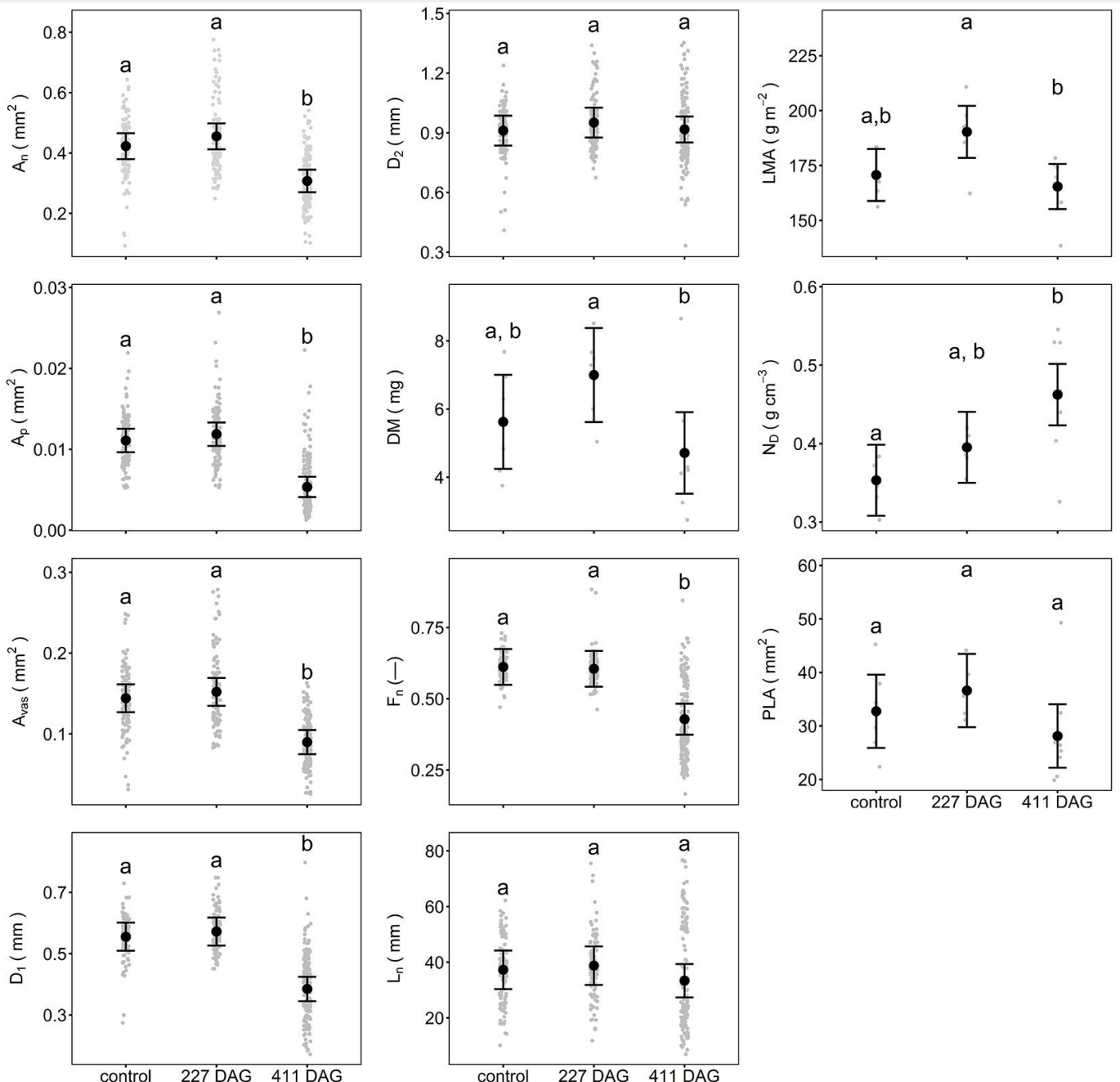
Tab. 2 - P-values from Tukey's HSD test showing the probability of differences in parameters between control needles and needles 227 or 411 days after girdling (DAG), and between needles 227 and 411 DAG. For an explanation and definition of the parameters, see Tab. 1.

\begin{tabular}{|c|c|c|c|}
\hline \multirow{2}{*}{ Parameter } & \multicolumn{3}{|l|}{$p$-value } \\
\hline & control $\times 227$ DAG & control $\times 411$ DAG & 227 DAG $\times 411$ DAG \\
\hline$A_{n}$ & 0.50 & $<0.001$ & $<0.001$ \\
\hline $\mathrm{A}_{\text {vas }}$ & 0.78 & $<0.001$ & $<0.001$ \\
\hline$A_{p}$ & 0.70 & $<0.001$ & $<0.001$ \\
\hline$D_{1}$ & 0.85 & $<0.001$ & $<0.001$ \\
\hline $\mathrm{D}_{2}$ & 0.70 & 0.99 & 0.74 \\
\hline $\mathrm{DM}$ & 0.37 & 0.003 & 0.07 \\
\hline $\mathrm{F}_{\mathrm{n}}$ & 0.99 & $<0.001$ & $<0.001$ \\
\hline$L_{n}$ & 0.94 & 0.64 & 0.43 \\
\hline LMA & 0.06 & 0.76 & 0.01 \\
\hline$N_{D}$ & 0.24 & $<0.001$ & 0.04 \\
\hline PLA & 0.68 & 0.54 & 0.15 \\
\hline
\end{tabular}

(Tab. 2). Although LMA did not differ significantly between girdled and control trees, the LMA of needles 227 DAG was significantly higher than the LMA of needles 411 DAG (Tab. 2).

Correlations among needle parameters $A_{n}, A_{p}, A_{\text {vas }}, D_{1}$, and $D_{2}$ were closely correlated in control needles as well as in needles 227 DAG (Fig. 3 - left panel). In con- trast, $\mathrm{F}_{\mathrm{n}}$ was not correlated with other parameters in control needles or needles 227 DAG. Correlations among the studied needle parameters 411 DAG were less pronounced than in control needles and needles 227 DAG (Fig. 3 - left panel). Only six correlations were observed in needles 411 DAG and, of these, $D_{1}$ was the most correlated needle parameter (Fig. 3 - left panel). Correlations between $\mathrm{L}_{n}$, LMA, $\mathrm{N}_{\mathrm{D}}$, and

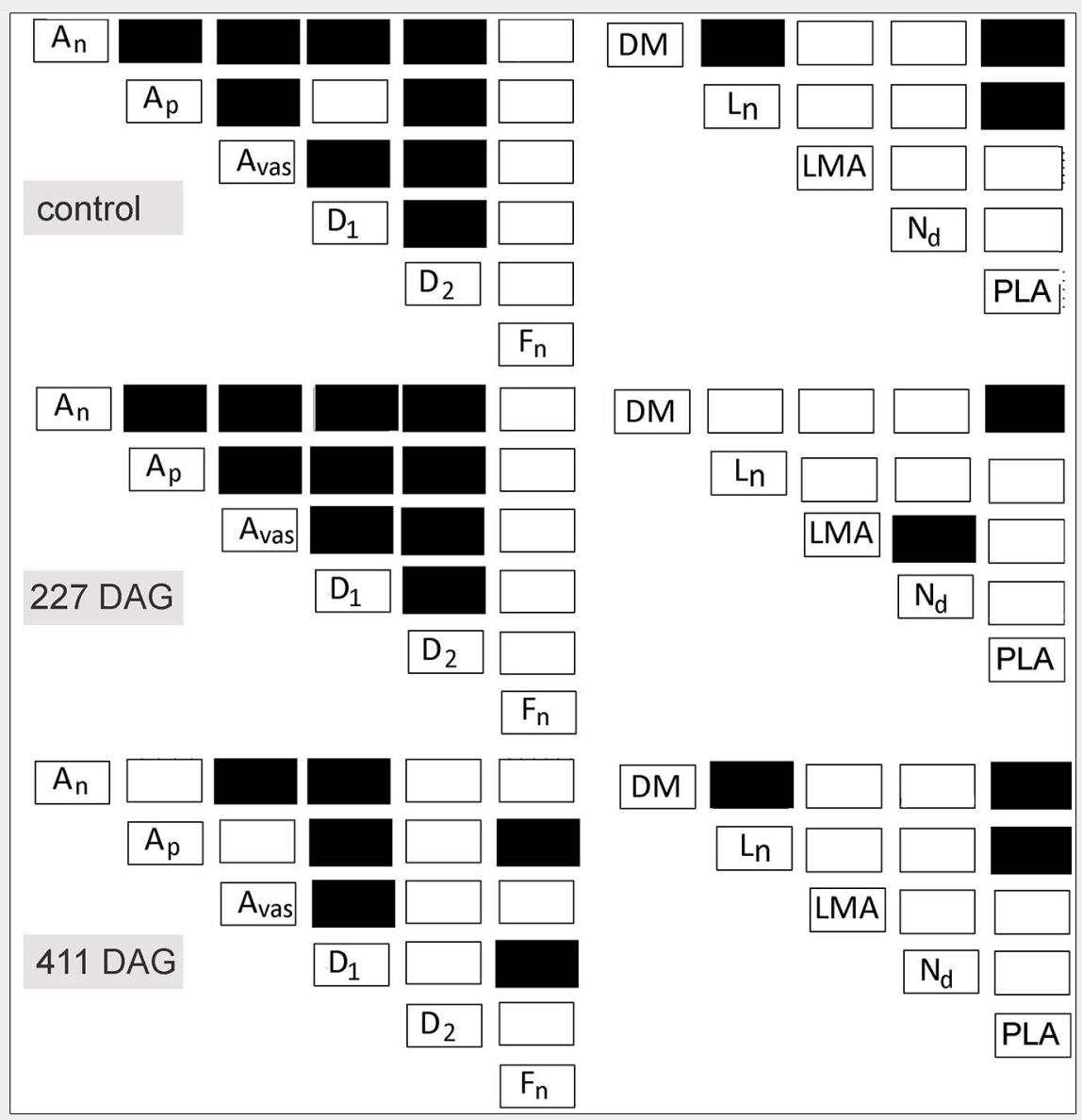

Fig. 3 - Correlation matrices (Pearson's product-moment correlation) among needle parameters for control trees (upper panels), trees 227 days after girdling (DAG - middle panels) and trees 411 DAG (lower panels). Pearson's correlation coefficient and significance level: black box $(r \geq 0.6 ; p<0.05)$; white box $(r<0.6 ; p>0.05)$;
PLA were relatively weak for both control and girdled trees (Fig. 3 - right panel). The only exception was a correlation between $L_{n}$ and PLA in control needles and needles 411 DAG, and a correlation between LMA and $\mathrm{N}_{\mathrm{D}}$ in needles $227 \mathrm{DAG}$. In addition, DM was correlated with $L_{n}$ and PLA in control needles and needles 411 DAG (Fig. 3 - right panel). Although DM was used for the calculation of LMA and $N_{D}$, they were not correlated.

\section{Discussion}

In this study, we observed several changes in needle structure in response to stem girdling 227 and 411 DAG, similarly to several previous investigations which measured physiological changes after stem girdling (Myers et al. 1999, Rivas et al. 2007, Urban \& Alphonsout 2007, Murakami et al. 2008). While the morphological and anatomical structures of needles 227 DAC were very similar to those of the control trees (the only marked difference was an increase of $9 \%$ in LMA, that is, the first hypothesis was not confirmed), seven of the eleven studied needle parameters were significantly different 411 DAG (in part, supporting our second hypothesis). The increase in LMA 227 DAG could be partly explained by a $5 \%$ increase in NSC in needles 227 DAG (Gebauer et al. 2017). LMA has previously been proposed as a useful indirect proxy for studying changes in carbohydrate concentrations (Day \& DeJong 1990, Domec \& Pruyn 2008, Lopéz et al. 2015). However, the increase in LMA in needles 227 DAG was higher than observed increases in NSC. This suggests that other mechanisms such as the accumulation of other NSCs or structural carbohydrates (i.e., an increase in the proportional representation of the cell wall) also contributed to the increase in LMA. Prolonged stemgirdling (411 DAG) decreased LMA and the concentration of insoluble NSC (starch) to the levels found in control needles. The initial increase in LMA after girdling and its subsequent decline was also found in Pinus canariensis C.Sm. seedlings (Lopéz et al. 2015) and Pinus ponderosa Dougal ex C. Lawson trees (Domec \& Pruyn 2008).

It has been reported that the reduction in stomatal conductance due to girdling results in lower transpiration, and therefore leads to a more favorable leaf water status (Williams et al. 2000). As cell expansion and division are positively affected by higher water potentials (Dale 1988), an increase in the number and/or dimensions of cells should be expected. However, no increase in needle structural parameters was observed in any of the girdled trees, indicating declining water availability during needle development. The likely reason for the decrease in the leaf water potential of girdled trees is that as the roots are gradually depleted of their carbohydrate reserves (Weaver \& McCune 1959), their surface area and absorptive capacity decrease, resulting in a subsequent increase 
in needle water shortage and eventual tree death (Negreros-Castillo \& Hall 1994, Pariona et al. 2003). This could be the reason why needles 411 DAG were smaller than control needles (supporting our second hypothesis). Moreover, needles 411 DAG had a smaller xylem area and a lower number of tracheids (Gebauer et al. 2017). Our results also correspond with a previous study (Baldwin 1934) in which poorer leaf development and smaller leaf size were observed for three deciduous species in the second season following stem girdling. We should note that several other factors (site conditions, climate, tree age, nutritional status, and tree health) also play an important role in needle development along with carbohydrate concentration and water status. For example, Scots pine needles growing on dunes with poor water availability had $A_{n}$ values similar to those of trees 411 DAG (Lukjanova \& Mandre 2008). In the present study, the mean values of $D_{1}(0.56$ $\mathrm{mm}$ ) and $D_{2}(0.91 \mathrm{~mm})$ for control trees were at the lower end or below the range reported for adult Scots pine trees (0.4$0.72 \mathrm{~mm}$ and $1.13-1.32 \mathrm{~mm}$, respectively Lin et al. 2002, Luomala et al. 2005, Lukjanova \& Mandre 2008). Interestingly, the reactions of $D_{1}$ and $D_{2}$ in response to girdling differed, as only $D_{1}$ was observed to have decreased in needles 411 DAG. It seems that needles 411 DAG still had a sufficient water supply during the early stages of needle development (i.e., in May 2014, the stem sap flow rate in trees 411 DAG was $59 \pm 10 \%$ of that of control trees). However, water was less available for xylem and phloem formation later in the season, leading to smaller values of $D_{1}$ (i.e., the transpiration rate of trees 411 DAC decreased to 31 $\pm 9 \%$ of that of control trees during the last two weeks in June 2014). This uneven development of $D_{1}$ and $D_{2}$ after stem girdling was also the reason why needles 411 DAG were flatter in form than in the control trees. The idea of needle growth being restricted by an insufficient supply of water is also supported by the observed increases in $N_{D}$ in needles 411 DAG, as $N_{D}$ is a foliar characteristic that generally increases in response to water limitation (Niinemets 2001). Nevertheless, the development of needle water potential after stem girdling should be investigated in future studies to demonstrate its influence on needle structural changes.

Regulatory mechanisms that determine needle size, and by extension needle form, are vital in that they allow plants to adapt to environmental conditions. It has been shown that anatomical changes in needles, from individuals to canopy level, are complex in nature (Gebauer et al. 2015, 2017). These features are likely regulated by both endogenous and environmental factors (Bongard-Pierce et al. 1996). Complexity in growth patterns was also observed in our study, as several needle parameters were closely inter-correlated in control trees and in trees 227 DAG. In contrast, a smaller number of correlations that achieved the required level of significance were observed in needles 411 DAG (partially supporting our third hypothesis). It was also observed that the structural development determining $F_{n}, N_{D}$, and LMA appeared to have driving factors that were independent of the other studied needle parameters, as correlations with other parameters were weak in all treatments. This suggests that gene expression in the needles of control and girdled trees could provide further insights into the regulatory mechanisms that determine the size and structural form of needles.

\section{Acknowledgements}

This work was funded by Czech project MSMT COST LD 13017 under the framework of the COST FP1106 network STReESS, by the Ministry of Education, Youth and Sports of the Czech Republic (Grant INTERTRANSFER LTT17033), and by the project "Indicators of Tree Vitality" (Grant No. CZ.1.07/2.3.00/20.0265) co-financed by the European Social Fund and the state budget of the Czech Republic.

\section{Conflict of Interest}

The authors declare that they have no conflicts of interest.

\section{References}

Baldwin $\mathrm{HI}$ (1934). Some physiological effects of girdling Northern hardwoods. Bulletin of the Torrey Botanical Club 61: 249-257. - doi: 10.2307/ 2480918

Bongard-Pierce DK, Evans MMS, Poethig RS (1996). Heteroblastic features of leaf anatomy in maize and their genetic regulation. International Journal of Plant Science 157: 331-340. doi: $10.1086 / 297353$

Dale JE (1988). The control of leaf expansion. Annual Review of Plant Physiology and Plant Molecular Biology 39: 267-295. - doi: 10.1146/ annurev.pp.39.060188.001411

Daudet FA, Ameglio T, Cochard H, Archilla O, Lacointe $A$ (2005). Experimental analysis of the role of water and carbon in tree stem diameter variations. Journal of Experimental Botany 56: 135-144. - doi: 10.1093/jxb/erio26

Day KR, DeJong TM (1990). Girdling of early season "Mayfire" nectarine trees. Journal of Horticultural Science 65: 529-534. - doi: 10.1080/0022 1589.1990.11516089

De Schepper V, Steppe K (2011). Tree girdling responses simulated by a water and carbon transport model. Annals of Botany 108: 11471154. - doi: 10.1093/aob/mcro68

De Schepper V, Steppe K, Van Labeke M, Lemeur $R$ (2010). Detailed analysis of double girdling effects on stem diameter variations and sap flow in young oak trees. Environmental and Experimental Botany 68: 149-156. - doi: 10.1016/ j.envexpbot.2009.11.012

Domec JC, Pruyn ML (2008). Bole girdling affects metabolic properties and root, trunk and branch hydraulics of young ponderosa pine trees. Tree Physiology 28: 1493-1504. - doi: 10.1093/treephys/28.10.1493

Fajstavr M, Giagli K, Vavrčík H, Gryc V, Urban J
(2017). The effect of stem girdling on xylem and phloem formation in Scots pine. Silva Fennica 51 (4): artID1760. - doi: 10.14214/sf.1760

Gebauer R, Cermák J, Plichta R, Spinlerová Z, Urban J, Volarík D, Ceulemans R (2015). Within canopy variation in needle morphology and anatomy of vascular tissues in a sparse Scots pine forest. Trees - Structure and Function 29: 1447-1457. - doi: 10.1007/s00468-015-1224-1

Gebauer R, Plichta R, Bednárová E, Foit J, Cermák V, Urban J (2017). How timing of stem girdling affects needle xylem structure in Scots pine. European Journal of Forest Research 14: 68. - doi: 10.1007/s10342-017-1090-z

Hara M, Oki K, Hoshino K, Kuboi T (2003). Enhancement of anthocyanin biosynthesis by sugar in radish (Raphanus sativus) hypocotyls. Plant Science 164: 259-265. - doi: 10.1016/S01689452(02)00408-9

Johnsen K, Maier C, Sanchez F, Anderson P, Butnor J, Waring R, Linder S (2007). Physiological girdling of pine trees via phloem chilling: proof of concept. Plant Cell and Environment 30: 128134. - doi: 10.1111/j.1365-3040.2006.01610.x

Lin J, Sampson DA, Deckmyn G, Ceulemans R (2002). Significant overestimation of needle surface area estimated based on needle dimensions in Scots pine (Pinus sylvestris). Canadian Journal of Botany 80: 927-932. - doi: 10.1139/ bo2-081

Lopéz R, Brossa R, Gil L, Pita P (2015). Stem girdling evidences a trade-off between cambial activity and sprouting and dramatically reduces plant transpiration due to feedback inhibition of photosynthesis and hormone signaling. Frontiers in Plant Science 6: 285. - doi: 10.3389/ fpls.2015.00285

Lukjanova A, Mandre M (2008). Anatomical structure and localisation of lignin in needles and shoots of Scots pine (Pinus sylvestris) growing in a habitat with varying environmental characteristics. Forestry Studies 49: 37-46. doi: 10.2478/v10132-011-0061-2

Luomala EM, Laitinen K, Sutinen S, Kellomäki S, Vapaavuori E (2005). Stomatal density, anatomy and nutrient concentrations of Scots pine needles are affected by elevated $\mathrm{CO}_{2}$ and temperature. Plant Cell and Environment 28: 733749. - doi: 10.1111/j.1365-3040.2005.01319.x

Morandi B, Rieger M, Grappadelli LC (2007). Vascular flows and transpiration affect peach (Prunus persica Batsch.) fruit daily growth. Journal of Experimental Botany 58: 3941-3947. - doi: 10.1093/jxb/erm248

Murakami PF, Schaberg PG, Shane JB (2008). Stem girdling manipulates leaf sugar concentrations and anthocyanin expression in sugar maple trees during autumn. Tree Physiology 28: 1467-1473. - doi: 10.1093/treephys/28.10.1467

Mwange KN, Hou HW, Cui KM (2003). Relationship between endogenous indole-3-acetic acid and abscisic acid changes and bark recovery in Eucommia ulmoides Oliv. after girdling. Journal of Experimental Botany 54: 1899-1907. - doi: 10.1093/jxb/erg204

Myers DA, Thomas RB, DeLucia EH (1999). Photosynthetic responses of loblolly pine (Pinus taeda) needles to experimental reduction in sink demand. Tree Physiology 19: 235-242. - doi: 10.1093/treephys/19.4-5.235

Negreros-Castillo P, Hall RB (1994). Four meth- 
ods for partial over story removal in tropical forests in Mexico. Journal of Environmental Management 41: 237-243. - doi: 10.1006/jema.19 94.1044

Niinemets U (2001). Global-scale climatic controls of leaf dry mass per area, density and thickness in trees and shrubs. Ecology 82: 453469. - doi: 10.1890/0012-9658(2001)082[0453: GSCCOL]2.0.CO;2

Noel ARA (1970). The girdled tree. Botanical Review 36: 162-195. - doi: 10.1007/BF02858959 Pang Y, Zhang J, Cao J, Yin SY, He XQ, Cui KM (2008). Phloem transdifferentiation from immature xylem cells during bark regeneration after girdling in Eucommia ulmoides Oliv. Journal of Experimental Botany 59: 1341-1351. - doi: 10.1093/jxb/erno41

Pariona W, Fredericksen TS, Licona JC (2003). Tree girdling treatments for timber stand improvement in Bolivian tropical forests. Journal of Tropical Forest Science 15: 583-592. [online] URL: http://www.jstor.org/stable/43595358

R Core Team (2015). R: a language and environment for statistical computing. R Foundation for Statistical Computing, Vienna, Austria. URL. [online] URL: http://www.R-project.org/ Rivas F, Gravina A, Agustí M (2007). Girdling effects on fruit set and quantum yield efficiency of PSII in two Citrus cultivars. Tree Physiology 27: 527-535. - doi: 10.1093/treephys/27. 4.527

Sellin A, Niglas A, Ounapuu E, Karusion A (2013). Impact of phloem girdling on leaf gas exchange and hydraulic conductance in hybrid aspen. Biologia Plantarum 57: 531-539. - doi: 10.1007/ s10535-013-0316-2

Setter TL, Brun WA, Brenner ML (1980). Effect of obstructed translocation of leaf abscisic acid on associated stomatal closure and photosynthesis decline. Plant Physiology 65: 1111-1115. doi: $10.1104 / p p .65 .6 .1111$

Taiz L, Zeiger E (2002). Plant Physiology ( $3^{\text {rd }}$ edn). Sinauer Associates Inc., Sunderland, MA, USA, pp. 672.

Urban L, Alphonsout L (2007). Girdling decreases photosynthetic electron fluxes and induces sustained photoprotection in mango leaves. Tree Physiology 27: 345-352. - doi: 10.1093/treephys/27.3.345

Weaver RJ, McCune SB (1959). Girdling: its relation to carbohydrate nutrition and development of Thompson Seedless, Red Malaga and Ribier grapes. Hilgardia 28: 421-456. - doi: 10.3733/hilg.v28n16p421
Williams LE, Retzlaff WA, Yang WG, Biscay PJ, Ebisuda N (2000). Effect of girdling on leaf gas exchange, water status, and non-structural carbohydrates of field-grown Vitis vinifera L. (cv. Flame Seedless). American Journal of Enology and Viticulture 51: 49-54. [online] URL: http:// www.ajevonline.org/content/51/1/49.short

Wilson BF, Gartner BL (2002). Effects of phloem girdling in conifers on apical control of branches, growth allocation and air in wood. Tree Physiology 22: 347-353. - doi: 10.1093/tree phys/22.5.347

Yan CF, Han SJ, Zhou YM, Wang CG, Dai GH, Xiao WF, Li MH (2012). Needle-age related variability in nitrogen, mobile carbohydrates, and $\delta 13 \mathrm{C}$ within Pinus koraiensis tree crown. PLoS ONE 7: e35076. - doi: 10.1371/journal.pone.0035076

Zuur AF, leno EN, Walker N, Saveliev AA, Smith $G M$ (2009). Mixed effects models and extensions in ecology with R. Springer, New York, USA, pp. 574. - doi: 10.1007/978-0-387-87458-6

Zwieniecki MA, Melcher PJ, Field TS, Holbrook NM (2004). A potential role for xylem-phloem interactions in the hydraulic architecture of trees: effects of phloem girdling on xylem hydraulic conductance. Tree Physiology 24: 911917. - doi: 10.1093/treephys/24.8.911 